\title{
Association of smoking and smoking cessation with major causes of mortality in the Asia Pacific Region: the Asia Pacific Cohort Studies Collaboration
}

F Barzi, R Huxley, K Jamrozik, T-H Lam, H Ueshima, D Gu, H C Kim and M Woodward

Tob. Control 2008;17;166-172

doi:10.1136/tc.2007.023457

Updated information and services can be found at:

http://tobaccocontrol.bmj.com/cgi/content/full/17/3/166

These include:

References This article cites 32 articles, 15 of which can be accessed free at:

http://tobaccocontrol.bmj.com/cgi/content/full/17/3/166\#BIBL

Rapid responses You can respond to this article at:

http://tobaccocontrol.bmj.com/cgi/eletter-submit/17/3/166

Email alerting Receive free email alerts when new articles cite this article - sign up in the box at service the top right corner of the article

Notes

To order reprints of this article go to:

http://journals.bmj.com/cgi/reprintform

To subscribe to Tobacco Control go to:

http:/journals.bmj.com/subscriptions/ 


\title{
Association of smoking and smoking cessation with major causes of mortality in the Asia Pacific Region: the Asia Pacific Cohort Studies Collaboration
}

\author{
F Barzi, ${ }^{1}$ R Huxley, ${ }^{1}$ K Jamrozik, ${ }^{2}$ T-H Lam, ${ }^{3}$ H Ueshima, ${ }^{4}$ D Gu, ${ }^{5}$ H C Kim, ${ }^{6}$ \\ $M$ Woodward ${ }^{7}$
}

${ }^{1}$ The George Institute for International Health, University of Sydney, Sydney, New South Wales, Australia; ${ }^{2}$ School of Population Health, University of Queensland, Herston,

Queensland, Australia;

${ }^{3}$ Department of Community

Medicine, School of Public

Health, University of Hong Kong,

Hong Kong; ${ }^{4}$ Department of

Health Science, Shiga University

of Medical Science,

Tsukinowacho Seta, Otsu,

Shiga, Japan; ${ }^{5}$ Department of

Evidence-Based Medicine, Fu

Wai Hospital, Chinese Academy

of Medical Sciences, Beijing, P R

China; ${ }^{6}$ Department of

Preventive Medicine, Yonsei

University College of Medicine,

Seoul, Korea; ' Department of

Medicine, Mount Sinai Medical

Center, New York, USA

Correspondence to:

Dr F Barzi, The George Institute for International Health, PO Box M201, Missenden Road,

Sydney, NSW 2050, Australia; fbarzi@george.org.au

MW presented some of these data at the 8th Asia Pacific

Conference on Tobacco or Health and the 10th Pfizer Asian Cardiology Symposium, both sponsored by Pfizer Inc. HCK presented some of these data at the 5th Annual Conference of the International Society for the Prevention of Tobacco Induced Diseases.

Received 5 September 2007 Accepted 31 January 2008

\begin{abstract}
Background: Although the dangers of smoking, and the benefits of quitting, are well established and understood in the West, smoking remains popular among Asian men. We investigated the associations between smoking (including ex-smoking) and major causes of mortality in Asian men and women, and compared with Australians and New Zealanders (ANZ)
\end{abstract}

Methods: An overview of 34 cohort studies in the Asia Pacific region involving 512676 individuals (81\% from Asia), followed up for a median of 6.7 years (20 804 deaths).

Results: Mortality rates for cause-specific and all causes of mortality were systematically higher for current compared with never smokers. Hazard ratios (HR) for overall and cause-specific mortality comparing currentsmokers with never smokers, ex- smokers with currentsmokers and comparing numbers of cigarettes smoked per day, were higher for ANZ than Asia $(p<0.001)$. For overall mortality, the $\mathrm{HR}(95 \% \mathrm{Cl})$ comparing currentsmoking with not was 1.37 (1.23 to 1.53) and 1.33 (1.26 to 1.40 ) in Asian men and women respectively. The corresponding figures in ANZ were 1.95 (1.81 to 2.09) and 1.85 (1.69 to 2.02). The HR for quitting in ANZ was 0.67 (0.63 to 0.71$)$ and 0.66 (0.58 to 0.74 ) in men and women respectively. Quitting smoking had a significant benefit among Asian men, the HR was 0.88 (0.81 to 0.97) after ignoring the first 3 years of follow-up. There was no evidence of benefit for Asian women, for whom exsmoking is rare.

Conclusions: Allowing for the recent uptake of smoking in Asia, its effects are comparable to those observed in ANZ. Stringent tobacco control measures and smoking cessation strategies are urgently required in Asia.

In the West, smoking has long been known to be a major cause of death and disability and has been estimated to kill one out of two smokers prematurely. ${ }^{1}$ Similarly, in Western populations, the benefits associated with quitting smoking have been clearly demonstrated and in general, are widely accepted by smokers and non-smokers. ${ }^{1-3}$ The vast majority of Westerners who currently smoke are aware that smoking increases their subsequent risk of cancer, cardiovascular disease and respiratory illnesses. Consequently, a significant proportion of smokers want, or have tried, to quit the habit. Over the past three decades, most developed countries have been successful in implementing comprehensive anti-tobacco measures that have resulted in substantial reductions in the prevalence of smoking such that the number of former smokers in countries such as the UK and Australia now exceeds that of current smokers. ${ }^{4}$

Across large parts of Asia the situation is the reverse and an estimated $50-70 \%$ of adult men are reported to be current smokers. ${ }^{5}$ In most Asian countries smoking cessation is a relatively infrequent event; a likely consequence of the wide cultural acceptance that smoking continues to enjoy in the region (particularly among men). ${ }^{467}$ For example, data from the China National Prevalence Survey (1996) showed the prevalence of former smokers to be only $10 \%$, and that the most common reason for quitting was ill health. Further, $60 \%$ of Chinese smokers have never contemplated quitting. ${ }^{6}$

Raising public awareness in Asia as to the health consequences caused by smoking is a vital first step in implementing effective tobacco control strategies and potentially would go some way towards reversing its cultural acceptability. However, only a small fraction of the studies that have reported on the associations between smoking and mortality have been conducted in these countries. Therefore, the objective of this current study is to provide reliable evidence as to the impact of smoking, and the likely benefits associated with quitting the habit, on total mortality and major causes of mortality among populations of the Asia Pacific region using data from the Asia Pacific Cohort Studies Collaboration (APCSC) ${ }^{8}$

\section{METHODS}

Details of study identification, data collection and event verification in the APCSC are described elsewhere. ${ }^{8}$ Briefly, studies were included if they had continued follow-up for at least 5000 personyears and had recorded vital status at the end of follow-up. Studies were excluded if entry was dependent upon a particular condition or risk factor. Mortality was classified according to the 9th Revision of the International Classification of Diseases (ICD). The outcomes investigated in this analysis were all causes of death, cancer, cardiovascular disease, respiratory disease (ICD9: 490$496,466,480-486,136.3,507,514,460-465$, 467-479, 487-489, 497-506, 508-513, 515-519, 010-019, 137) and injuries (including violence, suicide and any other trauma, ICD9: 800-999). Studies were classified as Asian if their participants were recruited from mainland China, Hong Kong, Japan, Korea, Singapore, Taiwan or Thailand; and ANZ if from Australia or New Zealand. 
Analyses were based on individual participant data and restricted to participants over 20 years of age. All data on cigarette smoking were based on self-report at the time of entry into one of the included studies. This analysis comprises studies that recorded whether individuals were current, former or never smokers; participants were grouped as "current" if they smoked currently, "never smokers" if they had never smoked and "former smokers (or ex-smokers)" if they had smoked in the past but reported having already quit at the time of entry. For those studies collecting information on the amount of cigarettes smoked per day (CPD), current smokers were classified in three approximately equal sized groups: $<20,20$ and $>20$ CPD; 20 cigarettes corresponds to one standard pack.

Cox proportional hazard models, adjusted for age and stratified by study, were used to derive the hazard ratios and corresponding 95\% CIs for death for "ex-smokers" as compared with "current" smokers and for "current" as compared with "never smoked". Since the effect of quitting on the reduction of mortality risk might have been underestimated due to participants stopping smoking because of health-related issues, a sensitivity analysis was also performed in which the first 3 years of follow-up were excluded. Hazard ratios for doseresponse of CPD were estimated using "never smoked" as the reference group. Confidence intervals were calculated using the method of floating absolute risks. ${ }^{9}$ Region- and sex-specific results were derived and heterogeneity of the estimated hazard ratios between groups was investigated through fitting interaction terms for region by smoking and sex by smoking. Heterogeneity of the estimated hazard ratios between three at risk age groups $(<65,65-74, \geqslant 75)$ was assessed using a $\chi^{2}$ test.

\section{RESULTS}

\section{Baseline characteristics and mortality data}

Of the 44 studies in APCSC, 34 (25 in Asia) provided data on current smoking status that distinguished former from never smokers. A total of 22 studies provided data on cigarette consumption for current smokers (table 1). Overall, information on 512676 participants (81\% from Asia) were included in the analyses.

Smoking habits varied by region and by sex. At baseline, in ANZ, $14 \%$ of women and $20 \%$ of men declared themselves as current smokers, and $21 \%$ and $43 \%$ of women and men, respectively, were reported as having quit smoking. In Asia, 59\% of men were current smokers and $11 \%$ were former smokers; the corresponding figures in women were $3 \%$ and $0.9 \%$. Female and male smokers in ANZ and male smokers in Asia had the same mean CPD (14); Asian women smoked, on average, 9 CPD.

In ANZ, during a median follow-up of 8.3 years, 3241 women and 5831 men died (table 2). In both sexes, cardiovascular disease was the leading cause of death (40\%), followed closely by cancer, (35\%). Approximately $7 \%$ of deaths were due to respiratory disease and $4 \%$ to injury. In Asia, over a median follow-up of 5.6 years a total of 3334 women and 8398 men died. The most common cause of death in men was cancer $(38 \%)$ and in women cardiovascular disease (40\%). Injury fatalities were more common in Asian men and women $(10 \%$ and $6 \%$, respectively) compared with participants from ANZ.

The age-adjusted mortality rates for all-cause mortality were systematically higher among current smokers compared with never smokers (table 2). In general, in ANZ mortality rates among former smokers were higher, or similar, to those of never smokers whilst in Asia they were higher or similar to those of current-smokers in Asia. The rates differences indicated a greater absolute effect of smoking on mortality risk in ANZ compared with Asia. For example, for all causes mortality the rates difference between current smokers and never smokers was equal to 80.1 and 48.8 per 10000 person years in ANZ men and women respectively. The corresponding figures in Asia were 22.9 and 31.2 per 10000 person-years.

\section{Hazard ratios for smoking-related mortality}

In ANZ, age-adjusted hazard ratios for current smokers, as compared with never smokers, showed a significant excess risk for all the outcomes except for injury mortality in women (table 3). There was no evidence of heterogeneity between sexes for any of the outcomes (range of $p$ values for interaction: 0.41-0.59). Compared with never smokers, current smokers had risks of mortality from all-site cancer and respiratory illness that were approximately two and five times higher, respectively; mortality from cardiovascular disease was also 60 to $80 \%$ higher among current smokers compared with never smokers. Smoking was associated with a smaller increase in risk, of about $50 \%$ and $30 \%$, for injury and other causes respectively.

In Asia, associations were less strong than those in ANZ for cancer, cardiovascular, respiratory and all-cause mortality (all $p$ values for regional interaction $<0.001$ ). Similar to ANZ, there were no evidence of any sex difference in the magnitude of the associations for any of the outcomes ( $p$ value for sex interaction: 0.43-0.96). Current smokers had a 61\% (95\% CI 29 to 100) greater risk of cancer in women and $44 \%$ (95\% CI 32 to 57 ) in men. In both sexes, cardiovascular mortality risk increased by more than $40 \%$, all-cause mortality by about one-third, and respiratory risk by about one-quarter.

There was a strong log-linear association between the number of cigarettes smoked per day and the risk of total mortality in both regions and in both sexes (all $\mathrm{p}$ values for linear trend $<0.001$; fig 1). The dose response relationship was stronger in ANZ than in Asia ( $p$ value for region interaction for men $<0.001$, for women $=0.014$ ). For example, comparing those who smoked 20 or more cigarettes per day to never smokers, the hazard ratio and 95\% CI for all-cause mortality was 1.52 (1.36 to 1.70$)$ and 1.30 (0.32 to 5.19) in men and women in Asia and 2.59 (2.32 to 2.89) and 2.94 (2.42 to 3.57) in men and women in ANZ. In Asia and ANZ there was no indication of a sex interaction ( $p$ value for interaction $\geqslant 0.23$ ).

\section{Hazard ratios for mortality among former smokers}

In ANZ, mortality risks were significantly reduced in former smokers as compared with current smokers for all the outcomes, with the exception of "other causes" in both sexes and injury in women. The risk of all-cause mortality was reduced by about one-third and similar reductions were estimated for the risk of cancer and cardiovascular disease; the risk of respiratory death was reduced by about two-thirds; and that of injury by $45 \%$ in men.

In Asia, there were no significant differences in most hazard ratios comparing former smokers with current smokers. The hazard ratio for all-cause mortality comparing former with current smokers was $0.98(0.92,1.05)$ in men and $1.03(0.86,1.24)$ in women. When the data were left-censored to exclude deaths during the first 3 years of follow-up, the hazard ratios comparing former with current smokers in males from Asia were 0.88 (0.81, 0.97 ) for all-cause mortality and $0.82(0.70-0.96)$ for cancer. Similarly the HRs were decreased but remained non significant, for cardiovascular and for mortality from other causes (table 3). By contrast, the hazard ratio for respiratory mortality was significantly increased in former versus current 
Table 1 Baseline summary statistics and details of studies included in the analyses

\begin{tabular}{|c|c|c|c|c|c|c|c|c|c|c|c|c|}
\hline \multirow[b]{2}{*}{ Country } & \multirow[b]{2}{*}{ Study } & \multirow[b]{2}{*}{$\mathbf{n}$} & \multirow[b]{2}{*}{$\begin{array}{l}\text { Baseline } \\
\text { year }\end{array}$} & \multirow{2}{*}{$\begin{array}{l}\text { Median } \\
\text { follow-up } \\
\text { (years) }\end{array}$} & \multirow[b]{2}{*}{$\begin{array}{l}\text { Mean age } \\
\text { (years) }\end{array}$} & \multirow[b]{2}{*}{$\begin{array}{l}\text { Women } \\
(\%)\end{array}$} & \multicolumn{3}{|l|}{ Women } & \multicolumn{3}{|l|}{ Men } \\
\hline & & & & & & & $\begin{array}{l}\text { Ex-smokers } \\
(\%)\end{array}$ & $\begin{array}{l}\text { Current } \\
(\%)\end{array}$ & $\begin{array}{l}\text { Mean } \\
\text { CPD }\end{array}$ & $\begin{array}{l}\text { Ex-smokers } \\
(\%)\end{array}$ & $\begin{array}{l}\text { Current } \\
(\%)\end{array}$ & Mean CPD \\
\hline Australia & Newcastle & 5929 & 1983-94 & 8.9 & 52 & 50 & 17.8 & 18.4 & 17 & 36.7 & 27.6 & 19 \\
\hline Australia & ALSA & 1610 & 1992-93 & 4.6 & 78 & 48 & 23.3 & 7.7 & 13 & 62.1 & 7.7 & 16 \\
\hline Australia & ANHF & 9277 & 1989-90 & 8.3 & 43 & 51 & 19.8 & 21.1 & 16 & 32.4 & 27.2 & 19 \\
\hline Australia & Busselton & 7789 & 1966-81 & 26.5 & 45 & 52 & 11.9 & 24.4 & 3 & 25.3 & 43.9 & 3 \\
\hline Australia & Canberra & 821 & 1991-92 & 9.4 & 77 & 45 & 24.9 & 9.7 & NA & 62.3 & 12.7 & NA \\
\hline Australia & Melbourne & 41285 & 1990-94 & 8.5 & 55 & 59 & 22.0 & 9.0 & 17 & 44.7 & 14.5 & 21 \\
\hline Australia & Perth & 10230 & 1978-94 & 5.7 & 45 & 48 & 18.3 & 21.1 & 15 & 31.3 & 29.6 & 18 \\
\hline Australia & WAAAA & 12203 & 1996-99 & 3.2 & 72 & 0.0 & NA & NA & NA & 59.9 & 10.9 & 13 \\
\hline NZ & Fletcher Challenge & 10326 & 1992-94 & 5.8 & 44 & 28 & 28.1 & 18.4 & 11 & 33.3 & 25.5 & 12 \\
\hline ANZ & Subtotal & 99470 & 1966-99 & 8.3 & 53 & 45 & 20.6 & 14.2 & 14 & 42.8 & 20.4 & 14 \\
\hline China & Anzhen & 8378 & 1991 & 4.3 & 54 & 55 & 2.4 & 10.3 & 9 & 8.9 & 50.8 & 14 \\
\hline China & Beijing Aging & 2092 & 1992 & 4.8 & 70 & 51 & 9.8 & 14.2 & 8 & 23.0 & 45.5 & 13 \\
\hline China & $\mathrm{CISCH}$ & 2167 & 1992-93 & 3.3 & 44 & 51 & 0.6 & 0.8 & 7 & 7.2 & 54.7 & 14 \\
\hline China & Fangshan & 2619 & 1991-92 & 3.6 & 47 & 67 & 2.2 & 21.5 & 4 & 6.2 & 74.6 & 8 \\
\hline China & $\begin{array}{l}\text { Guangzhou } \\
\text { Occupational }\end{array}$ & 166695 & $1985-98$ & 7.3 & 42 & 22 & 0.0 & 1.3 & 7 & 0.5 & 60.4 & 13 \\
\hline China & $\begin{array}{l}\text { Seven Cities } \\
\text { Cohorts }\end{array}$ & 10811 & 1987 & 2.7 & 54 & 55 & 1.9 & 16.8 & NA & 8.0 & 57.0 & NA \\
\hline China & Xi'an & 1695 & 1976 & 19.7 & 44 & 34 & 0.5 & 11.9 & 10 & 2.2 & 54.0 & 15 \\
\hline China & Yunnan & 6581 & 1992 & 4.5 & 56 & 3 & NA & NA & NA & 14.3 & 69.7 & 12 \\
\hline Hong Kong & Hong Kong & 2983 & 1985-91 & 2.5 & 79 & 57 & 17.6 & 10.8 & 7 & 41.2 & 29.1 & 11 \\
\hline Japan & Akabane & 1834 & 1985-86 & 11.0 & 54 & 56 & 0.3 & 1.0 & 8 & 20.8 & 61.9 & 23 \\
\hline Japan & $\begin{array}{l}\text { Civil Service } \\
\text { Workers }\end{array}$ & 9240 & 1990-92 & 6.7 & 47 & 33 & 3.1 & 11.4 & NA & 25.7 & 50.9 & NA \\
\hline Japan & Hisayama & 1601 & 1961 & 24.6 & 56 & 56 & 0.9 & 16.7 & NA & 4.0 & 76.2 & NA \\
\hline Japan & Konan & 1226 & 1987-95 & 6.4 & 52 & 55 & 1.0 & 4.7 & 11 & 14.3 & 61.6 & 22 \\
\hline Japan & Miyama & 1073 & $1988-90$ & 6.6 & 61 & 56 & 2.9 & 7.0 & 12 & 24.9 & 57.7 & 21 \\
\hline Japan & Ohasama & 2240 & 1992-93 & 4.1 & 60 & 64 & 0.5 & 2.3 & NA & 11.4 & 51.1 & NA \\
\hline Japan & Saitama & 3615 & $1986-90$ & 11.0 & 55 & 62 & 2.3 & 7.7 & 14 & 21.0 & 62.5 & 21 \\
\hline Japan & Shibata & 2350 & 1977 & 20.0 & 57 & 58 & 0.3 & 4.4 & 10 & 5.7 & 72.2 & 20 \\
\hline Japan & Shigaraki Town & 3730 & $1991-97$ & 4.4 & 57 & 59 & 1.6 & 8.0 & 13 & 22.4 & 59.0 & 22 \\
\hline Japan & Shirakawa & 4640 & 1974-79 & 17.5 & 48 & 54 & 0.4 & 5.4 & NA & 7.7 & 69.9 & NA \\
\hline Singapore & Singapore Heart & 2321 & 1982-97 & 14.6 & 41 & 49 & 0.7 & 3.0 & NA & 13.8 & 40.5 & NA \\
\hline Singapore & Singapore NHS92 & 3305 & 1992 & 6.2 & 39 & 52 & 0.4 & 3.0 & NA & 11.7 & 34.8 & NA \\
\hline S. Korea & KMIC & 160242 & 1992 & 4.0 & 44 & 33 & 0.5 & 0.4 & NA & 21.3 & 57.5 & NA \\
\hline Taiwan & CVDFACTS & 5729 & 1988-96 & 6.0 & 47 & 55 & 0.1 & 1.5 & NA & 7.2 & 48.0 & NA \\
\hline Taiwan & Kinmen & 2545 & 1993-97 & 2.9 & 63 & 49 & 1.3 & 5.2 & NA & 16.9 & 50.3 & NA \\
\hline Thailand & EGAT & 3494 & 1985 & 11.4 & 43 & 23 & 1.8 & 6.3 & NA & 17.9 & 54.3 & NA \\
\hline Asia & Subtotal & 413206 & 1961-98 & 5.6 & 44.8 & 32 & 0.9 & 3.3 & 9 & 10.7 & 58.6 & 14 \\
\hline
\end{tabular}

Sudies were: ALSA, Australian Longitudinal Study of Aging; ANHF, Australian National Heart Foundation; ANZ, Australians and New Zealanders; CISCH, Capital Iron and Steel Company Hospital Cohort; EGAT, Electricity Generating Authority of Thailand; KMIC, Korean Medical Insurance Company; WAAAA, Western Australian Abdominal Aortic Aneurysm Screening Program.

$\mathrm{CPD}$, number of cigarettes smoked per day by current smokers; NA, not available.

smokers: 1.37 (1.03, 1.84). By comparison, left-censoring did not influence the results from Australia.

\section{Age specific hazard ratios}

Smoking was associated with a significant increased risk of allcause mortality at all ages but it had a relatively stronger impact among individuals at risk at "younger" ages in ANZ and Asia ( $p$ values for age interaction $<0.001$ in ANZ and 0.007 in Asia; table 4). In both regions the hazard ratio for all-cause mortality among current smokers was significantly higher among individuals less than 65 years of age compared with those aged over 75 years ( $p$ value for interaction $<0.001$ ). The benefits derived from quitting smoking were significant at all ages in ANZ, being greater among younger individuals who presumably would have been smoking for fewer years and had quit at younger age. From the youngest to the oldest age at risk group, quitting appeared to decrease the risk of mortality in ANZ, respectively by 43,37 and $24 \%$ ( $p$ value for age interaction $<0.001$ ). In Asia, where the effect of quitting smoking was less clear, only those in the youngest age group who had quit had a significant $10 \%$ reduction in the risk of all-cause mortality compared with continuing smokers.

\section{CONCLUSIONS}

Our findings, based on data from over half a million individuals, show that cigarette smoking is associated with a significant increase in the risk of cancer, cardiovascular disease and anycause mortality, for both sexes in Asian and Caucasian populations of the Asia Pacific region. Smoking is also a significant risk factor for fatal respiratory disease and deaths from "other causes" except in the case of Asian women, among whom smoking is rare. Furthermore, there was evidence of a positive association of smoking with death from injury in cohorts from ANZ. The excess risks of mortality from all causes 
Table 2 Age standardised rates (per 10000 person-years) of cause-specific and all causes mortality according to baseline smoking habit, by region and sex

\begin{tabular}{|c|c|c|c|c|c|c|c|c|}
\hline \multirow[b]{3}{*}{ Causes of death } & \multicolumn{4}{|l|}{ ANZ } & \multicolumn{4}{|l|}{ Asia } \\
\hline & \multicolumn{2}{|l|}{ Men } & \multicolumn{2}{|c|}{ Women } & \multicolumn{2}{|l|}{ Men } & \multicolumn{2}{|c|}{ Women } \\
\hline & $\mathrm{n}$ & Rate (SE) & $\bar{n}$ & Rate (SE) & $\mathrm{n}$ & Rate (SE) & $\mathrm{n}$ & Rate (SE) \\
\hline Never & 458 & $19.1(1.0)$ & 676 & $16.5(0.7)$ & 703 & $18.7(0.8)$ & 785 & $11.8(0.4)$ \\
\hline Ex & 1005 & $27.1(1.2)$ & 235 & $19.0(1.4)$ & 429 & $28.6(1.5)$ & 38 & $22.4(5.4)$ \\
\hline Current & 591 & $46.2(2.0)$ & 261 & $36.0(2.4)$ & 2019 & $28.0(0.7)$ & 103 & $17.8(1.9)$ \\
\hline Ex & 1057 & $24.7(1.7)$ & 194 & $14.9(1.2)$ & 376 & $27.7(1.5)$ & 74 & $34.5(6.3)$ \\
\hline Current & 723 & $55.6(2.2)$ & 249 & $34.5(2.4)$ & 1481 & $27.5(0.8)$ & 193 & $32.5(2.5)$ \\
\hline \multicolumn{9}{|l|}{ Respiratory: } \\
\hline Never & 63 & $2.0(0.3)$ & 99 & $2.2(0.2)$ & 165 & $5.8(0.5)$ & 268 & $4.0(0.2)$ \\
\hline Ex & 197 & $3.7(0.3)$ & 31 & $2.4(0.5)$ & 125 & $8.6(0.8)$ & 38 & $7.8(2.3)$ \\
\hline Current & 194 & $14.4(1.1)$ & 72 & $10.0(1.2)$ & 350 & $8.1(0.5)$ & 43 & $6.4(1.1)$ \\
\hline \multicolumn{9}{|l|}{ Other: } \\
\hline Never & 210 & $7.8(0.61)$ & 310 & $7.6(0.5)$ & 354 & $9.7(0.6)$ & 452 & $6.3(0.3)$ \\
\hline Ex & 396 & $9.7(0.70)$ & 78 & $6.7(0.8)$ & 191 & $12.7(1.0)$ & 23 & $10.7(4.0)$ \\
\hline Current & 161 & $12.6(1.06)$ & 77 & $11.0(1.4)$ & 810 & $12.0(0.5)$ & 59 & $11.5(2.2)$ \\
\hline \multicolumn{9}{|l|}{ All causes: } \\
\hline Never & 1361 & $54.7(1.7)$ & 1997 & $46.1(1.2)$ & 2018 & $58.4(1.4)$ & 2744 & $42.1(0.8)$ \\
\hline Ex & 2725 & $68.3(1.9)$ & 558 & $44.9(2.1)$ & 1219 & $84.5(2.7)$ & 176 & $82.9(11.0)$ \\
\hline Current & 1745 & $134.8(3.4)$ & 686 & $94.9(3.9)$ & 5161 & $81.3(1.4)$ & 414 & $73.3(4.4)$ \\
\hline
\end{tabular}

The overall Asia Pacific Cohort Studies Collaboration population served as the base for age standardisation.

ANZ, Australians and New Zealanders; SE, standard error.

Table 3 Hazard ratios and 95\% Cls for cause specific mortality and overall mortality, by region and sex

\begin{tabular}{|c|c|c|c|c|c|c|}
\hline & \multicolumn{2}{|l|}{ ANZ } & \multirow[b]{2}{*}{ p Value* } & \multicolumn{2}{|l|}{ Asia } & \multirow[b]{2}{*}{ p Value* } \\
\hline & Men & Women & & Men & Women & \\
\hline \multicolumn{7}{|l|}{ All cancer: } \\
\hline Ex vs current & $0.72(0.65$ to 0.80$)$ & 0.65 (0.54 to 0.78 ) & & 1.02 (0.91 to 1.14$)$ & $1.10(0.74$ to 1.63$)$ & \\
\hline Ex vs current $\dagger$ & 0.68 (0.60 to 0.78$)$ & 0.65 (0.53 to 0.80 ) & & $0.82(0.70$ to 0.96$)$ & 0.73 (0.37 to 1.44$)$ & \\
\hline \multicolumn{7}{|l|}{ All cardiovascular: } \\
\hline Ex vs current $\dagger$ & 0.68 (0.61 to 0.77$)$ & 0.70 (0.56 to 0.86$)$ & & 0.88 (0.75 to 1.04$)$ & $0.99(0.66$ to 1.05$)$ & \\
\hline \multicolumn{7}{|l|}{ Respiratory: } \\
\hline Current vs never & 5.42 (4.04 to 7.27$)$ & 4.56 (3.33 to 6.24 ) & 0.59 & 1.24 (1.03 to 1.50$)$ & $1.23(0.89$ to 1.70$)$ & 0.96 \\
\hline Ex vs current & $0.34(0.27$ to 0.42$)$ & $0.32(0.21$ to 0.49$)$ & & $1.18(0.95$ to 1.48$)$ & $1.26(0.79$ to 2.01$)$ & \\
\hline Ex vs current $\dagger$ & $0.31(0.24$ to 0.40$)$ & 0.26 (0.15 to 0.44$)$ & & 1.37 (1.03 to 1.84$)$ & 1.17 (0.58 to 2.34$)$ & \\
\hline \multicolumn{7}{|l|}{ Injury: } \\
\hline Current vs never & $1.26(1.02$ to 1.55$)$ & 1.38 (1.07 to 1.78$)$ & 0.50 & $1.23(1.09$ to 1.40$)$ & $1.16(0.88$ to 1.54$)$ & 0.81 \\
\hline Ex vs current & $0.94(0.78$ to 1.15$)$ & 0.75 (0.55 to 1.04$)$ & & $0.90(0.76$ to 1.06$)$ & $0.83(0.50$ to 1.37$)$ & \\
\hline Ex vs current $\dagger$ & $0.99(0.78$ to 1.28$)$ & 0.77 (0.52 to 1.12$)$ & & $0.69(0.45$ to 1.08$)$ & $0.90(0.21$ to 3.85$)$ & \\
\hline \multicolumn{7}{|l|}{ All causes: } \\
\hline Current vs never & 1.95 (1.81 to 2.09 ) & 1.85 (1.69 to 2.02$)$ & 0.41 & 1.37 (1.23 to 1.53$)$ & $1.33(1.26$ to 1.40$)$ & 0.65 \\
\hline Ex vs current & $0.67(0.63$ to 0.71$)$ & 0.66 (0.58 to 0.74$)$ & & $0.98(0.92$ to 1.05$)$ & $1.03(0.86$ to 1.24$)$ & \\
\hline Ex vs current $\dagger$ & 0.66 (0.62 to 0.72 ) & 0.65 (0.57 to 0.74 ) & & 0.88 (0.81 to 0.97$)$ & $1.00(0.75$ to 1.32$)$ & \\
\hline
\end{tabular}

${ }^{*} p$ Value for sex interaction.

$\dagger$ After censoring of the first 3 years of follow-up.

ANZ, Australians and New Zealanders. 
Figure 1 Hazard ratios for all-cause mortality by number of cigarettes per day (base $=$ never smokers), by region and sex. Lines show $95 \%$ Cls. ANZ, Australians and New Zealanders.

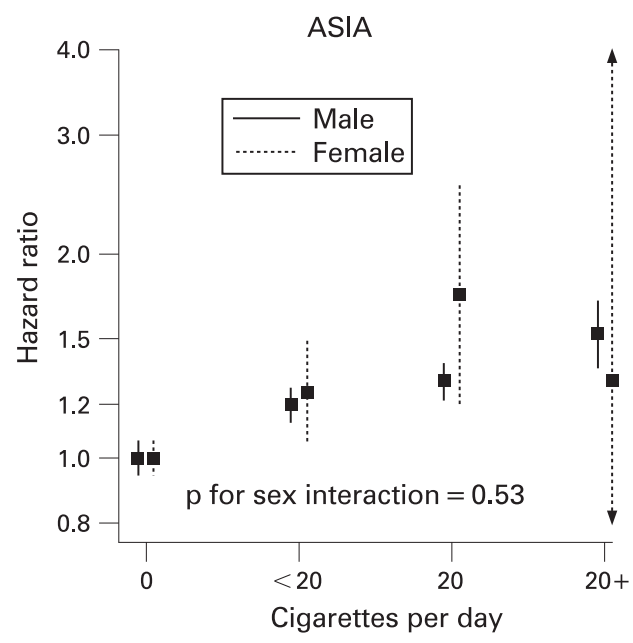

were apparent at all ages but were consistently greater among younger individuals in Asia and ANZ.

For all-cause mortality the excess risks associated with smoking were significantly higher in ANZ compared with Asia. Current smokers in ANZ had twice the risk compared with never smokers, whereas in Asia, current smokers had a one-third higher risk. The magnitude of these estimates, as well as the smaller observed effect among Asian cohorts, are consistent with previous findings from studies conducted in Australia $^{10}$ New Zealand ${ }^{11}$ and Europe ${ }^{12-14}$ China, ${ }^{15-18}$ Taiwan, ${ }^{19}{ }^{20}$ Japan $^{21-23}$ and Korea. ${ }^{24}$

Although the relative risks associated with smoking were generally lower in Asia compared with ANZ, particularly for women, this is likely to reflect reported differences in the maturity of the smoking epidemic across the region ${ }^{525-28}$ rather than it being indicative of any physiological, or genetic, differences between Asians and non-Asians. ${ }^{29}$ A shorter length of study follow up among the Asian cohorts may also have underestimated the effects, given that the risks of smoking are determined not only by the amount smoked and the age at which smoking commences, but also by the duration of smoking. Consequently, the full impact of smoking on health in the region has yet to be realised and is unlikely to be apparent for at least another decade.

Differences in the reasons for quitting may also account for some of the variation in the impact of smoking between the regions. In China, most former smokers quit due to an already established illness, ${ }^{6}$ by which time, stopping smoking would have little effect on altering disease progression; hence such patterns of smoking cessation are associated with only modest reductions in relative risk or in some instances, an actual increase in the risk (due to the problem of reverse causality).
Although our analyses did not adjust for education or socio economic status or personality, variables that were not collected in the APCSC, our finding of a positive association between smoking and mortality from injury in cohorts from ANZ is consistent with findings from a meta-analysis of four studies from the USA and Northern Europe. ${ }^{30}$ In that meta-analysis, a dose-response relationship between smoking and injuries was observed, and this persisted after adjustment for alcohol consumption and socioeconomic status. It has been suggested that the apparent association between smoking and injury might be confounded by personality type; individuals who smoke are postulated to engage in risky behaviours resulting in an increased propensity towards incurring an injury. ${ }^{31}$ Studies have also shown that people with mental illness are about twice as likely to smoke as others. ${ }^{32}{ }^{33}$ Thus, whether the relationship is causal or due to confounding remains a matter of ongoing debate and for investigation by future studies.

Importantly, findings from the current study demonstrate the effectiveness of quitting smoking on reducing the risk of mortality across all populations in the Asia Pacific region, although the benefits tended to be greater for former smokers in cohorts from ANZ compared with those from Asia. In ANZ, quitting smoking was associated with a reduction of $30 \%$ in the risk of all-cause mortality compared with one of about a $10 \%$ among male former smokers in Asia. The benefits of quitting smoking were also greater among younger individuals $(<65$ years) presumably because they have smoked for fewer years compared with older individuals, and older individuals often quit too late after having serious illnesses.

We found an increased risk of $37 \%$ in respiratory mortality in former versus current smokers. This is likely due to reverse causality and is consistent with the increased risk of chronic

Table 4 Hazard ratios and $95 \%$ Cls for all-cause mortality by region and age at risk group

\begin{tabular}{lllll}
\hline Status/age group & ANZ & p Value* & Asia & p Value* \\
\hline $\begin{array}{l}\text { Current vs never: } \\
\quad 65\end{array}$ & $2.21(1.98$ to 2.47$)$ & $<0.001$ & $1.35(1.27$ to 1.42$)$ & 0.007 \\
$65-75$ & $2.35(2.13$ to 2.59$)$ & & $1.40(1.29$ to 1.52$)$ & \\
$75+$ & $1.47(1.35$ to 1.61$)$ & & $1.18(1.09$ to 1.28$)$ & \\
Ex vs current: & & & \\
$\quad<65$ & $0.57(0.51$ to 0.64$)$ & $<0.001$ & $0.90(0.83$ to 0.99$)$ & \\
$65-75$ & $0.63(0.58$ to 0.70$)$ & & $1.18(1.04$ to 1.35$)$ & \\
$75+$ & $0.76(0.69$ to 0.83$)$ & & $1.04(0.92$ to 1.17$)$ & \\
\hline
\end{tabular}

${ }^{*} p$ Value for age interaction

ANZ, Australians and New Zealanders. 


\section{What this paper adds}

- Despite the relative immaturity of the smoking epidemic across large parts of Asia, smoking is associated with a substantial increase in the risk of mortality from all causes.

- Quitting smoking reduces the risk of premature death in Asia where smoking cessation is a rare occurrence.

- Culturally-specific tobacco control strategies are urgently needed across Asia to curb the smoking epidemic.

obstructive pulmonary disease in former smokers in a cohort study of Chinese retired $\mathrm{men}^{18}$ and similar findings for deaths due to respiratory disease in Taiwan. ${ }^{19}$ We attempted to remove the potential for reverse causality by eliminating the first 3 years of follow-up, the overall effect of which was a general lowering of the risks among male former smokers in Asia (with the exception of respiratory illness). By comparison, left-censoring had no impact in ANZ, which lends support to the aforementioned idea that individuals in Asia are more likely to quit smoking due to reasons of ill health.

The current analyses are limited by the lack of information on the duration and age at which smoking commenced, both of which are more important determinants of subsequent risk than the actual amount smoked. ${ }^{34}$ Related to this, we also lacked data on the time since quitting smoking and consequently, we were unable to examine how risk may have evolved over time among former-smokers. Furthermore, APCSC analyses were based on self-reported cigarette consumption at baseline, and information on change in smoking habits during follow-up was available from too few studies to enable any meaningful analysis to be undertaken. Finally, the individual studies used different methods to verify cause of death, which would have resulted in an underestimation of the risks associated with smoking. Moreover, these methods will have varied over time and the lack of standardisation could have had some unpredictable effect on the results.

Currently, interventions that only focus on preventing people from starting to smoke will do little to prevent an estimated 1 billion deaths due to smoking by the end of the 21st century, 100 million of which will occur in China alone. ${ }^{4}$ A low level of awareness as to the harmful effects of cigarette smoking and of the health and economic benefits associated with quitting, ${ }^{35}$ the mistaken belief that quitting could be harmful to some chronic smokers, combined with a lack of comprehensive tobacco control programmes, ${ }^{6}$ may explain much of the ongoing popularity of smoking in China and other Asian countries. Effective tobacco control strategies and implementation of smoke-free policies ${ }^{36}$ are urgently needed across Asia in order to assist many smokers to quit and thus to prevent the large number of deaths that are predicted to occur if current smoking patterns $_{\text {persist. }}{ }^{27}$

Acknowledgements: This project has received support from a National Health and Medical Research Council of Australia program grant and an unrestricted educational grant from Pfizer. HCK is supported by a grant from the Korea Health 21 R\&D Project, Ministry of Health and Welfare, Republic of Korea (A/4/152).

Funding: This project received support from a National Health and Medical Research Council of Australia program grant and an unrestricted educational grant from Pfizer Inc. The sponsors had no influence on design, analysis or interpretation of results and took no part in the writing of this paper.

Competing interests: None.

\section{REFERENCES}

1. Doll R, Peto R, Boreham J, et al. Mortality in relation to smoking: 50 years' observations on male British doctors. BMJ 2004;328:1519-33.

2. Jacobs DR, Adachi H, Mulder I, et al. Cigarette smoking and mortality risk: twentyfive-year follow-up of the Seven Countries Study. Arch Intern Med 1999;159:733-40.

3. Godfredsen NS, Holst C, Prescott E, et al. Smoking reduction, smoking cessation, and mortality: a 16-year follow-up of 19,732 men and women from The Copenhagen Centre for Prospective Population Studies. Am J Epidemiol 2002;156:994-1001.

4. Mackay J, Eriksen M. The tobacco atlas. Geneva, Switzerland: World Heath Organization, 2002.

5. Martiniuk ALC, Lee CMY, Lam TH, et al. The fraction of ischaemic heart disease and stroke attributable to smoking in the WHO Western Pacific and South-East Asian regions. Tob Control 2006;15:181-8.

6. Yang G, MA J, Chen A, et al. Smoking cessation in China: findings from the 1996 national prevalence survey. Tob Control 2001;10:170-4.

7. World Health Organization. Tobacco or health: a global status report. Geneva, Switzerland: World Health Organization, 1997.

8. Woodward M, Barzi F, Martiniuk A, et al. Cohort profile: the Asia Pacific Cohort Studies Collaboration. Int J Epidemiol 2006;35:1412-16.

9. Woodward M. Epidemiology: study design and data analysis. 2nd edn. Boca Raton, Florida: Chapman and Hall/CRC, 2004.

10. Simons LA, Simons J, McCallum, et al. Impact of smoking, diabetes and hypertension on survival time in the elderly: the Dubbo Study. Med J Aust 2005;182:219-22.

11. Hunt D, Blakely $T$, Woodward A, et al. The smoking-mortality association varies over time and by ethnicity in New Zealand. Int J Epidemiol 2005;34:1020-8.

12. Prescott $\mathbf{E}$, Osler $\mathrm{M}$, Andersen PK, et al. Mortality in women and men in relation to smoking. Int J Epidemiol 1998;27:27-32.

13. Marang-van de Mheen PJ, Davey Smith G, Hart CL, et al. Are women more sensitive to smoking then men? Findings from the Renfrew and Paisley study. Int J Epidemiol 2001;30:787-92.

14. Nilsson S, Cartensen JM, Pershagen G. Mortality among male and female smokers in Sweden: a 33 year follow-up. J Epidemiol Community Health 2001;55:825-30.

15. Yuan JM, Ross RK, Wang $\mathrm{XL}$, et al. Morbidity and mortality in relation to cigarette smoking in Shanghai, China. A prospective male cohort study. JAMA 1996;275:1646-50.

16. Chen ZM, Xu Z, Collins $\mathrm{R}$, et al. Early health effects of the emerging tobacco epidemic in China: 16-year prospective study. JAMA 1997;278:1500-4.

17. Lam TH, He Y, Li LS, et al. Mortality attributed to cigarette smoking in China. JAMA 1997;278:1505-8.

18. Lam TH, He Y, Shi QL, et al. Smoking, quitting, and mortality in a Chinese cohort of retired men. Ann Epidemiol 2002;12:316-20.

19. Wen CP, Tsai SP, Chen CJ, et al. The mortality risks of smokers in Taiwan. Part I: cause specific mortality. Prev Med 2004;39:528-35.

20. Wen CP, Cheng TY, Lin CL, et al. The health benefits of smoking cessation for adult smokers and for pregnant women in Taiwan. Tob Control 2005;14(Suppl I):56-61.

21. Uno F, Ishikawa $S$, Nakamura $Y$, et al. Smoking and risk of all-cause mortality: the Jichi Medical School (JMS) Cohort Study. J Epidemiol 2005;15:173-9.

22. Hozawa A, Ohkubo T, Yamaguchi J, et al. Cigarette smoking and mortality in Japan: the Miyagi Cohort Study. J Epidemiol 2004;14(Suppl 1):7-12.

23. Murakami Y, Ueshima H, Okamura T, et al. Life expectancy among Japanese of different smoking status in Japan: NIPPON DATA80. J Epidemiol 2007;17:31-7.

24. Kim IS, Ohrr H, Jee SH, et al. Smoking and total mortality: Kangwha Cohort Study, 6 year follow-up. Yonsei Med J 1993;34:212-22.

25. Wynder EL, Fujita Y, Harris RE, et al. Comparative epidemiology of cancer between the United States and Japan: a second look. Cancer 1991:67:746-63.

26. Jee SH, Samet JM, Ohrr H, et al. Smoking and cancer risk in Korean men and women. Cancer Causes Control 2004;15:341-8.

27. Peto R, Chen ZM, Boreham J. Tobacco - the growing epidemic. Nat Med 1999; 5:15-17.

28. Lopez AD, Collishaw NE, Piha T. A descriptive model of the cigarette epidemic in developed countries. Tob Control 2004;3:242-7.

29. Woo KS, Robinson JTC, Adams MR, et al. Differences in the effect of cigarette smoking on endothelial function in Chinese and white adults. Ann Intern Med 1997; 127:372-5.

30. Leistikow BN, Martin DC, Jacobs J, et al. Smoking as a risk factor for accident death: a meta-analysis of cohort studies. Accid Anal Prev 2000;32:397-405.

31. Doll R, Peto R, Wheatley $\mathrm{K}$, et al. Mortality in relation to smoking: 40 years' observations on male British doctors. BMJ 1994;309:901-11.

32. Lasser K, Boyd JW, Woolhandler S, et al. Smoking and mental illness. A population based prevalence study. JAMA 2000;284:2606-10.

33. Glassman AH, Helzer JE, Covio LS, et al. Smoking, smoking cessation, and major depression. JAMA 1990;264:1546-9.

34. Doll R, Peto R. Mortality in relation to smoking: 20 years' observations on male British doctors. BMJ 1796;2:1525-36

35. Huxley R, Jamrozik K, Lam TH, et al. Impact of smoking and smoking cessation on lung cancer mortality in the Asia-Pacific Region. Am J Epidemiol 2007;165:1280-6.

36. Fichtenberg $\mathbf{C M}$, Glantz SA. Effect of smoke-free workplaces on smoking behaviour: systematic review. BMJ 2002;325:188. 


\section{APPENDIX}

\section{APCSC Executive committee}

M Woodward (Chair), R Huxley, X Fang, D F Gu, Y Imai, T H Lam, W H Pan, A Rodgers, I Suh, H C Kim, H Ueshima.

\section{Participating studies and principal collaborators}

Aito Town: A Okayama, H Ueshima, H Maegawa; Akabane: M Nakamura, N Aoki; Anzhen02: Z S Wu; Anzhen: C H Yao, Z S Wu; Australian Longitudinal Study of Aging: M Luszcz; Australian National Heart Foundation: T A Welborn; Beijing Aging: Z Tang; Beiijing Steelworkers: L S Liu, J X Xie; Blood Donors' Health: R Norton, S Ameratunga, S MacMahon, G Whitlock; Busselton: M W Knuiman; Canberra-Queanbeyan: H Christensen; Capital Iron and Steel Company: X G Wu; CISCH: J Zhou, X H Yu; Civil
Service Workers: A Tamakoshi; CVDFACTS: W H Pan; East Beijing: Z L Wu, L 0 Chen, G L Shan; Electricity Generating Authority of Thailand: P Sritara; Fangshan: D F Gu, X F Duan; Fletcher Challenge: S MacMahon, R Norton, G Whitlock, $R$ Jackson; Guangzhou: Y H Li; Guangzhou Occupational: T H Lam, C 0 Jiang; Hisayama: Y Kiyohara, H Arima, M lida; Hong Kong: J Woo, S C Ho; Huashan: Z Hong, M S Huang, B Zhou (deceased); Kinmen: J L Fuh; Konan: H Ueshima, Y Kita, S R Choudhury; KMIC: I Suh, S H Jee, I S Kim; Melbourne: G G Giles; Miyama: T Hashimoto, K Sakata; Newcastle: A Dobson; Ohasama: Y Imai, T Ohkubo, A Hozawa; Perth: K Jamrozik, M Hobbs, R Broadhurst; Saitama: K Nakachi; Seven Cities: X H Fang, S C Li, 0 D Yang; Shanghai Factory Workers: Z M Chen; Shibata: H Tanaka; Shigaraki Town: Y Kita, A Nozaki, H Ueshima; Shirakawa: H Horibe, Y Matsutani, M Kagaya; Singapore Heart: K Hughes, J Lee; Singapore NHS92: D Heng, S K Chew; Six Cohorts: B F Zhou, H Y Zhang; Tanno/ Soubetsu: K Shimamoto, S Saitoh; Tianjin: Z Z Li, H Y Zhang; Western Australia AAA Screenees: P Norman, K Jamrozik; Xi'an: Y He, T H Lam; Yunnan: S X Yao.

\section{The Lighter Side}

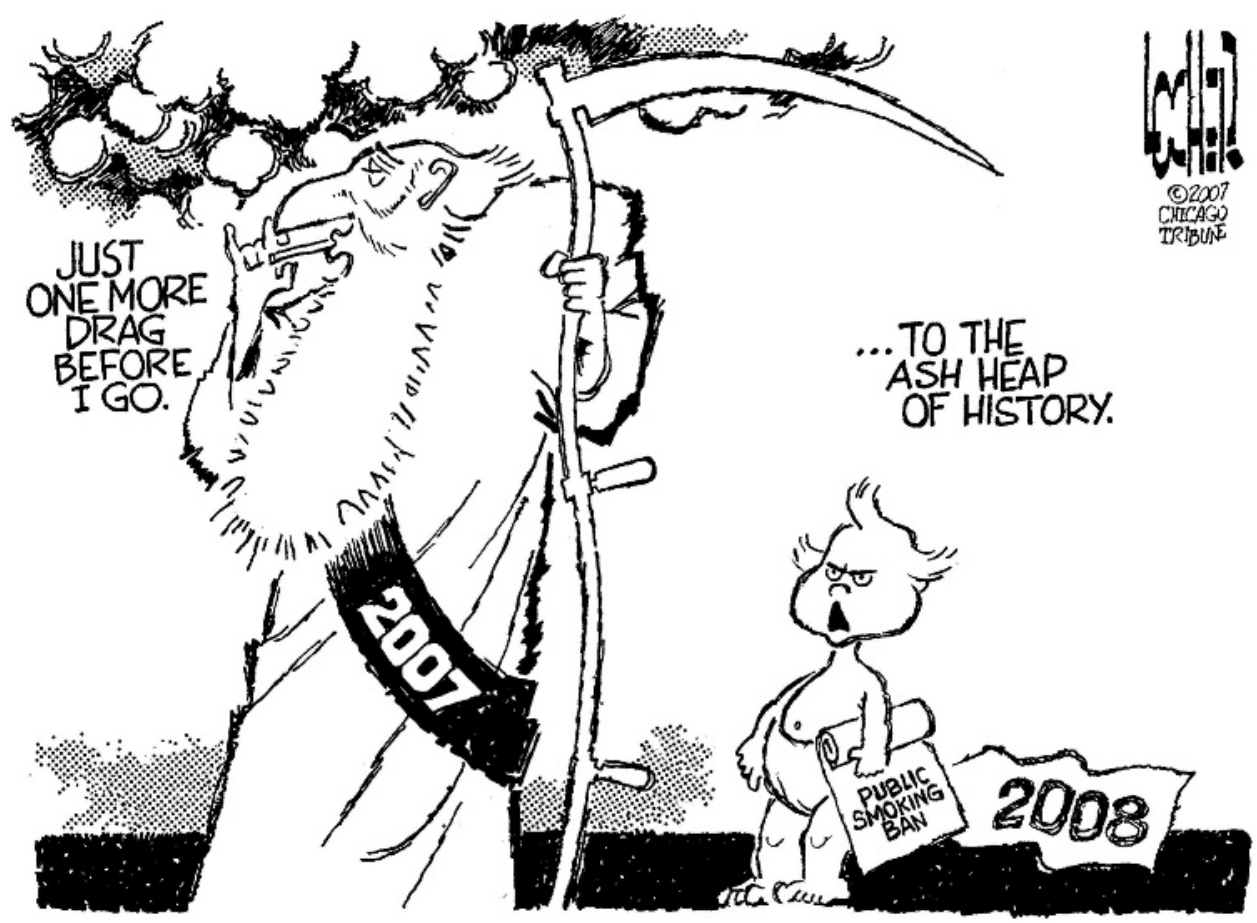

Dick Locher, Chicago Tribune. (c) Tribune Media Services. All rights reserved. Reprinted with permission. 